\title{
La dramatización musical del romancero en Educación Primaria para el desarrollo de la competencia social y ciudadana
}

The musical dramatization of the Spanish ballads in Primary Education as a tool for developing social and civic competences

\author{
María Isabel de Vicente-Yagüe Jara ${ }^{1}$ \\ isabelvyague@um.es \\ María Marco Martínez \\ maria.marco@um.es \\ Universidad de Murcia, España
}

\section{Resumen:}

La pervivencia de una metodología conductista de raigambre tradicional, sostenida por la enseñanza especializada de materias dispuestas de manera deliberadamente inconexa, merma toda posible realización de proyectos interdisciplinares destinados a la conformación de un currículo integrado y, como consecuencia, el correcto desarrollo de las competencias básicas vigentes en el actual contexto educativo de convergencia europea. En este sentido, se presenta en las áreas de Educación artística y de Lengua castellana y literatura de la etapa de Educación Primaria una metodología intertextual que conecta poesía y música, a partir de dramatizaciones musicales inspiradas en romances procedentes de la antología Flor nueva de romances viejos de Ramón Menéndez Pidal, musicalizados por el

\begin{abstract}
:
The persistence of a behaviorist methodology with traditional roots, supported by specialized teaching of subjects arranged in a deliberately disjointed manner, decreases any possible realization of interdisciplinary projects aimed at the creation of an integrated curriculum. It also impedes the proper development of basic competences set in the current educational context of European convergence. In this sense, an intertextual methodology connecting poetry and music, through musical dramatizations inspired in romances from the Spanish anthology Flor nueva de romances viejos, by Ramón Menéndez Pidal, with music by the folklorist Joaquín Díaz González, is presented in the areas of Art Education and Spanish language and Literature of Primary Education. The main aim of this project is to develop social and
\end{abstract}

1 Dirección para correspondencia (correspondence address):

María Isabel de Vicente-Yagüe Jara. Dpto. de Didáctica de la Lengua y la Literatura (español). Facultad de Educación. Universidad de Murcia. Campus Universitario de Espinardo. 30100 Murcia (España). 
La dramatización musical del romancero en Educación Primaria para el desarrollo de la competencia social y ciudadana

María Isabel de Vicente-Yagüe Jara y María Marco Martínez

folclorista Joaquín Díaz González, con el fin de desarrollar la competencia social y ciudadana. El carácter social, cooperativo, expresivo, comunicativo y lúdico de la dramatización musical, como instrumento pedagógico, potencia en el alumnado la mejora de sus habilidades sociales, su desarrollo emocional, un comprometido y responsable trabajo en equipo, la comprensión crítica de la realidad representada, un diálogo respetuoso y solidario y, en definitiva, el ejercicio de una convivencia pacífica y democrática, en conexión con los propósitos perseguidos en la adquisición de la competencia social y ciudadana.

\section{Palabras clave:}

Competencia social y ciudadana; dramatización musical; romance; intertextualidad; interdisciplinariedad; aprendizaje cooperativo; re-escritura creativa. civic competences. The social, cooperative, expressive, communicative and playful nature of the musical dramatization, as a pedagogical tool, encourages students to improve their social skills, emotional development, committed and responsible teamwork, critical understanding of the reality represented, a respectful and supportive dialogue and, ultimately, the pursuit of peaceful and democratic coexistence, in connection with the purposes pursued in the acquisition of social and civic competences.

\section{Key words:}

Social and civic competences; musical dramatization; romance; intertextuality; interdisciplinarity; cooperative learning; creative re-writing.

\section{Résumé:}

La survivance d'une méthodologie behavioriste traditionnelle, soutenue par I'enseignement spécialisé de matières disposées de façon délibérément décousue, réduit toute possible réalisation de projets interdisciplinaires destinés à l'élaboration d'un programme intégré et, par conséquent, le développement correct des compétences clés en vigueur dans l'actuel contexte éducatif de convergence européenne. Dans ce sens, on présente dans les matières d'Éducation artistique et de Langue castillane et littérature de l'étape d'Enseignement Primaire une méthodologie intertextuelle qui raccorde poésie et musique, à partir de mises en scène musicales inspirées des romances provenant de l'anthologie Flor nueva de romances viejos de Ramón Menéndez Pidal, mises en musique par le folkloriste Joaquín Díaz González, afin de développer la compétence sociale et civique. Le caractère social, coopératif, expressif, communicatif et ludique de la mise en scène musicale, comme instrument pédagogique, suscite chez les élèves l'amélioration de ses habiletés sociales, son développement émotionnel, un travail en équipe impliqué et responsable, la compréhension critique de la réalité jouée, un dialogue respectueux et solidaire et, en somme, l'exercice d'une coexistence pacifique et démocratique, par rapport aux buts poursuivis pour l'acquisition de la compétence sociale et civique.

\section{Mots clés:}

Compétence sociale et civique; mise en scène musicale; romance; intertextualité; interdisciplinarité; apprentissage coopératif; réécriture créative.

Fecha de recepción: 23-2-2014

Fecha de aceptación: 5-3-2014 


\section{Introducción}

No abundan en la etapa de Educación Primaria las propuestas de interacción didáctica entre las áreas de Educación artística y de Lengua castellana y literatura porque, a pesar de los muchos beneficios que ello reportaría a la conformación del currículo integrado (Torres, 2006), todavía pervive con profundo afianzamiento una metodología conductista de raigambre tradicional. Este tipo de metodología se viene sosteniendo por la enseñanza especializada de materias dispuestas de manera deliberadamente inconexa con respecto a otros campos disciplinares y bajo la supervisión del saber; una metodología basada en la estrategia exclusiva de utilizar como instrumentos de enseñanza el dictado de apuntes del profesor o el libro de texto normalizado para cada nivel, cuyos contenidos conceptuales solamente pueden ser asumidos de modo memorístico o a través de ejercicios miméticos, controlados por la previsión de solución única.

Por tanto, el hecho de que apenas existan iniciativas interdisciplinares entre la Educación artística -en su sección de Música- y la Lengua casteIlana y literatura es la "punta del iceberg", es decir, es una fría manifestación superficial de un problema educativo oculto y de gran magnitud, que ha "congelado" el discurrir natural y recomendable de los contenidos curriculares para beneficio de la cognición humana. El currículo Educación Primaria, así como las programaciones docentes derivadas del mismo, no suelen aprovechar el caudal de la literatura de los clásicos hispánicos para desarrollar los conocimientos musicales, y viceversa, lo que conlleva que tampoco se desenvuelvan de forma adecuada habilidades y destrezas como la comprensión lectora, la lectura expresiva en voz alta, la creatividad a través de la escritura de invención e, incluso, la expresión corporal de proyección rítmica y estética. No debe olvidarse, por otra parte, que las propuestas interdisciplinares de este tipo permitirían plantear con naturalidad tareas cooperativas entre alumnos para lograr un proyecto común resolviendo retos y problemas (Decroly y Boon, 1922; Kilpatrick, 1918), y de esta manera se gestionarían coherentemente las relaciones entre las competencias básicas y, en especial, el desarrollo de la competencia social y ciudadana. El hecho de inhibirlas ocasiona, pues, que la enseñanza de la Literatura o de la Música por separado solo conduzca hacia actividades puntuales, cuyo agente habitual es el alumno como individuo y cuyo solucionario está previsto de antemano. 
De acuerdo con el marco legislativo actual emanado de la Ley Orgánica 2/2006, de 3 de mayo, de Educación, el profesorado español ha de afrontar la educación en competencias básicas desde cada asignatura y también entre todas las implicadas en el nivel en el que imparte docencia (MEC, 2006, p. 43058), y ello se consigue cuando delimita recursos didácticos comunes y diseña intervenciones de aula donde el alumnado trabaja de manera globalizada y transversal (Escamilla, 2009, p. 25). Así pues, se persigue en este trabajo presentar, analizar y justificar un tipo de metodología intertextual, que conecta los lenguajes literario y musical y, por tanto, sus áreas correspondientes, a través de prácticas sociales de dramatización musical, con el fin de desarrollar la competencia social y ciudadana del alumnado.

\section{Lenguaje poético y musical en el aula: un modelo didáctico intertextual de enfoque semiótico}

El concepto de la intertextualidad responde a un término científico de carácter semiótico ideado por Julia Kristeva (1978) a partir de la teoría sobre el dialogismo cultural formulada por Mijail Bajtin (1970). Dicho concepto se fundamenta en la retroalimentación textual, de forma que cualquier texto -y de modo privilegiado aquellos que son considerados "literatura"- es un espacio de encuentro múltiple de otros textos, pues conforma su tejido como una red de significación plural e interconectada. Kristeva otorga rumbo nuevo a estas ideas sobre la dinámica de la textualidad, desde sus estudios sobre la literatura como manifestación de la ciencia social de la cultura, cuando define con exactitud la intertextualidad en calidad de actividad que conforma todos los textos como un mosaico de citas por absorción y transformación de otro texto. De esta manera, podemos entender la intertextualidad de Kristeva como un conjunto de lenguajes que conviven en un mismo texto literario. Ello supone que la lectura intertextual contiene implicaciones hermenéuticas que no se formulan a través de la lectura heurística. A diferencia de esta, la lectura hermenéutica es espiral y no lineal, acoge diversos significados simultáneamente y se expande hacia un mundo ilimitado de asociaciones tanto referenciales como hipotextuales (Gabbay, 2010).

A la luz de un modelo didáctico intertextual basado en tales premisas, el discurso literario no puede ser concebido como una actividad escri- 
tural individualista ni autónoma, sino que debe ser reconocido por la realidad de su construcción retórica y social. Dicha construcción revela una mezcla de lenguajes que establecen un diálogo de distintas voces, las cuales interactúan con el lector, pasando este de un estado pasivo a un oyente activo.

En coherencia con la metodología de la intertextualidad, la lectura ha de ser una herramienta utilizada como reminiscencia de la escritura que se traspone en el texto. Los grandes autores de la Semiótica -Barthes, Kristeva y Genette- han remarcado como un saber contundente basado en la experiencia intertextual que no existe texto fuera del contexto. Los mensajes verbales deben ser relacionados con el conjunto de los contextos de emisión y recepción, para obtener una interpretación lectora adecuada con respecto al significado pragmático del texto y una perspectiva creativa que suscite nuevos sentidos a la obra en el imaginario de cada lector. Por ello, la mejor situación para emplear la intertextualidad es a través de la escritura hipertextual (Genette, 1982; Mendoza, 2012), en la cual quedan vinculados varios tipos de textos y de contextos.

Todo ello se traduce en un lugar para la poesía, en un espacio poético donde encuentran albergue las más diversas voces y géneros de la literatura de la manera elástica y transversal que El Quijote cervantino y otros clásicos han sabido mostrar con su arte para todos. Así, cabe hablar de "clásicos redivivos" en el sentido de que la lectura se vuelve creativa cuando establece deseo de correspondencia con el hipotexto clásico, el cual revive en hipertextos anudados al mismo (Caro, 2006). Además, la dimensión hipertextual del clásico, su condición de texto infinito, susceptible de recreaciones e interpretaciones varias, conecta con la capacidad innata más antigua del individuo para generar hipertextos: la imaginación.

La dimensión que la semiótica otorga a la intertextualidad es la de la fundamentación metodológica de la generación textual. Lógicamente, entre otras opciones, puede ser aprovechable para establecer nuevas vías de análisis literario (Fernández Bueno, 2009), pero de ningún modo debemos reducir su entendimiento a una simple modalidad de análisis de fuentes e influencias, pues la intertextualidad no consiste únicamente en el reconocimiento de fragmentos textuales o intenciones de autor, sino que ella misma es la que posibilita encuentros entre lo dispar para suscitar nuevas creaciones derivadas de las pretensiones de las obras presuntamente originales. Y apuntamos "presuntamente" por- 
que, en realidad, la intertextualidad revela que la idea puntual de origen se desbarata en la idea recíproca de don-deuda, cuando se entiende la literatura desde el momento en el que adviene la creación literaria por "invención", es decir, por llamada de obras diversas a modo de hilos necesarios para poder tejer el tapiz de conocimiento de una obra nueva. La intertextualidad no concuerda, pues, con la noción de influencia propia del academicismo filológico, sino con la condición imprevisible y dialógica de la imaginación humana.

La intertextualidad fomenta la creatividad a través de textos verbales y no verbales, pues exige un diseño democrático acogiendo el diálogo como estrategia básica del aprendizaje significativo. Por tanto, se debe partir desde conocimientos asimilados, aprendidos y comprendidos hacia nuevas metas cognitivas, utilizando como herramienta el diálogo y la literatura en contextos totalmente diferentes.

\section{El romancero para la vida: tradición artística e innovación creativa}

Habitan las raíces del romance, siguiendo el criterio de datación basado en su testimonio escrito, en el siglo $\mathrm{XV}$, conviviendo entre finales de la Edad Media y los inicios de la Edad Moderna. Se ha de destacar en este sentido que debido a la transmisión oral propia del género, la datación exacta de este se convierte en una empresa harto difícil. Los estudios de Menéndez Pidal, quien conjugó la investigación con el trabajo de campo, son fundamentales para determinar dicho origen. Así pues, según Menéndez Pidal (1953), editor a su vez del romancero que nos ocupa, la procedencia del romance deriva de la actividad de los juglares, de naturaleza anónima en su mayoría, y guarda una relación genealógica con los cantares de gesta franceses de siglos anteriores, evidente en los procedimientos métricos. La teoría neotradicionalista de Menéndez Pidal sostiene que los romances aparecieron de una fragmentación de los cantares de gesta o epopeyas medievales, perviviendo los versos de mayor interés o popularidad que generación tras generación fue recordando a lo largo de la historia, con el añadido de numerosas variantes.

Los romances, en atención a su doble vertiente artístico-creativa, ya eran definidos por Menéndez Pidal como "poemas épico-líricos breves que se cantan al son de un instrumento, sea en danzas corales, sea en 
reuniones tenidas para recreo simplemente o para el trabajo en común" (2010, p. 11). De hecho, diversas fuentes musicales recogen romances e incluyen sus melodías; así, podemos mencionar el Cancionero musical editado por Asenjo Barbieri (1890), tratados como el De musica libri septem de Francisco de Salinas (1577) o métodos para aprender a tocar la vihuela, como los Tres libros de música en cifras para vihuela de Alonso de Mudarra (1546) o el Libro de música de vihuela de Diego Pisador (1552). Igualmente, el vínculo entre la música y los romances ya posee desde hace décadas importantes estudios musicológicos y filológicos, entre los que podemos citar los de Martínez Torner (1923) o Devoto (1943). No obstante, no es nuestra intención indagar en esta línea de investigación propia de los hispanistas y musicólogos más avezados y eruditos, sino proyectar este tesoro literario-musical hacia el mundo educativo de la niñez.

Así pues, el romance es un género que permite ser planteado a partir de una gran diversidad de estrategias metodológicas en el aula de Educación Primaria y Secundaria. Con el fin de lograr un aprendizaje significativo y contextualizado, es posible diseñar tareas que realicen un recorrido conectado desde la Edad Media hasta nuestros tiempos. Véase como ejemplo el trabajo compositivo a semejanza del romancero dirigido por Lozano (2004) y titulado además muy oportunamente "Hacia una Nueva Flor de Romances Nuevos: Experiencia didáctica con el Romancero Tradicional". El objetivo de una tarea de escritura de este tipo no era competir con el estilo creativo del romancero, sino comprender los mecanismos de la tradición, al partir de noticias de prensa actual para comunicar, cual juglar, los hechos a la manera medieval e histórica.

Probablemente la más valiosa de las joyas del romancero tradicional sea la antología editada por Ramón Menéndez Pidal Flor nueva de romances viejos. Dicho volumen se encuentra dividido en seis partes, según la temática, los personajes o la procedencia de los romances: romances de la destrucción de España, romances de Bernardo del Carpio, romances de venganza, romances del $\mathrm{Cid}$, romances moriscos y de frontera, romances pastoriles y villanescos.

En Flor nueva de romances viejos, Menéndez Pidal (2010, pp. 3941), según él mismo nos destaca en el proemio del volumen, no solo ha fundido versiones ya publicadas por Grimm, Durán, Wolf o Menéndez Pelayo, sino que también ha incluido variantes procedentes de textos antiguos ignorados por estos críticos, de nuevas versiones modernas de la 
tradición oral e, incluso, de su propia inventiva. En este sentido, Menéndez Pidal afirma que "vivir es variar" (2010, p. 40) y que la tradición ha revivido en su ánimo, en el que se han producido variantes, fruto de una personal conexión con esta poesía tradicional. Por otra parte, el estudio de las variantes de ciertos romances ha permitido establecer la procedencia de los mismos, a través del método geográfico (Menéndez Pidal, 1973). También Moreno (2009) investigaba los márgenes del romancero, exponiendo los diferentes tipos de versiones que escapan a un esquema general para una determinada zona: versiones fragmentarias, anómalas, minoritarias, viajeras, falsificaciones y versiones vulgatas.

En conexión con tal circunstancia oral de variantes y versiones del romance, cabría citar la propuesta didáctica de Barrios (2004) acerca de la música popular de tradición oral. Barrios pretende, desde una perspectiva significativa y constructivista, que el alumnado lleve a cabo una investigación de campo, recopilando y seleccionando canciones de la tradición oral de su tierra (en este caso de Extremadura) mediante la ayuda de familiares, vecinos y mayores. El beneficio de acciones de este tipo se traduce en un aprendizaje implicado, que incita al gusto estético del alumnado por esta tradición cultural y lo convierte en partícipe de su propia expresión y difusión.

Por todo lo comentado con anterioridad, este romancero para la vida debe trasladarse al aula de Educación Primaria. Los alumnos se convierten así en difusores de dichos versos, en juglares de nuestro tiempo, en comunicadores históricos, logrando que las obras sigan perviviendo en la memoria actual, alejadas del olvido y de un posible y temido vacío en nuestra propia historia, en nuestra cultura.

\section{La dramatización para la educación en la competencia social y ciudadana}

Aprender a conocer, aprender a hacer, aprender a vivir y aprender a ser son los pilares en los que debería asentarse la educación; así lo reflejó Jacques Delors (1996) en su célebre informe titulado La educación encierra un tesoro, apostando por un aprendizaje integral a lo largo de toda la vida. En el desarrollo del propósito de afrontar los desafíos de la sociedad actual y futura con acciones competentes y humanas, tendría gran importancia la recomendación del Parlamento y el Consejo Euro- 
peos a los estados miembros (Unión Europea, 2006), al impulsar una reforma educativa basada en el desarrollo de las competencias clave para el aprendizaje permanente. En España surgió, por tanto, la Ley Orgánica 2/2006, de 3 de mayo, de Educación y, tras su amparo, los Reales Decretos para las etapas educativas de Educación Primaria y Educación Secundaria Obligatoria, los cuales recogerían el desarrollo de las competencias básicas.

Así pues, de acuerdo con lo formulado en el Real Decreto 1513/2006 de Educación Primaria, la competencia social y ciudadana permite comprender la realidad social en la que se vive, afrontar la convivencia empleando el juicio ético y ejercer la ciudadanía democrática en la creciente pluralidad de la sociedad actual. Del mismo modo, dicha competencia implica aceptar las diferencias, ser tolerante, resolver conflictos, respetar los valores y la cultura personal y colectiva de los otros, con actitud constructiva, reflexión crítica y talante responsable ante el cumplimiento de los derechos y obligaciones cívicas.

El trabajo para el desarrollo de la competencia social y ciudadana en el ámbito escolar ha de encauzarse por medio de acciones de participación y cooperación responsable, que impliquen actitudes solidarias, respetuosas y comprometidas. Así pues, se pretende el cultivo de la convivencia democrática a partir del fomento de la dimensión interpersonal y ética del alumno, promoviendo sentimientos prosociales de altruismo, solidaridad, compasión o conductas de ayuda (Marina y Bernabeu, 2007, pp. 98-111). En este sentido, estimamos convincente el razonamiento de Fernández Herrero que postula, como efecto de una educación axiológica, la moralización democrática de la escuela: "toda educación es, en esencia, axiológica: siempre que se educa, se educa para un fin -un modelo de persona- que es el que marca las metas y los objetivos educativos" (Fernández Herrero, 2010, p. 5). Por tanto, la educación debe ser moral, debe procurar un conjunto de valores esenciales para la formación de ese modelo de persona deseable. Además, esta misma autora, preocupada por la competencia social y ciudadana que nos ocupa, incide en el desarrollo paralelo de la competencia comunicativa, entendida como promotora de la convivencia en las sociedades democráticas, plurales y multiculturales, a través de los recursos de la argumentación, el diálogo y la discusión.

En el área de Lengua castellana y literatura, el aprendizaje de la lengua como instrumento comunicativo permite el desarrollo de habilida- 
des y destrezas para la convivencia y el entendimiento entre iguales, supone asumir la propia expresión como vía primordial de apertura a los demás y, considerando equivalentes y adecuadas las diferentes lenguas en sus funciones de comunicación y representación, sanciona prejuicios e imágenes estereotipadas del mundo (MEC, 2006, p. 43071). Por otro lado, las tareas de interpretación y creación propias del área de Educación artística favorecen el trabajo en equipo, fomentando la cooperación, la asunción de responsabilidades, el compromiso, el respeto y el acuerdo en el grupo, así como la satisfacción por un producto final, fruto del esfuerzo común (MEC, 2006, p. 43084).

Por su parte, Llach y Alsina, desde las áreas de Didáctica de la Lengua y Didáctica de las Matemáticas, proponen una serie de actividades genéricas para el desarrollo del conjunto de competencias básicas, entre las que podemos destacar para el caso concreto de la competencia social y ciudadana en la materia lingüística las siguientes: presentaciones en público y trabajos en grupo, con el fin de aceptar las opiniones de los demás y ser capaz de exponer las propias de forma eficaz; actividades de contraste lingüístico y literario, para cultivar la diversidad cultural; y apropiación crítica de aspectos históricos y sociales que permitan comprender la evolución de la lengua y la literatura, para fomentar el respeto y evitar prejuicios (Llach y Alsina, 2009, p. 80).

En este sentido, el carácter social, lúdico y cooperativo de la dramatización musical, como instrumento pedagógico, potencia en el alumnado el desarrollo de sus habilidades sociales, el trabajo en equipo, la mejora de su autoestima y el aumento de la confianza en sí mismo, entre otros aspectos. Laferrière vincula las técnicas dramáticas a una educación social, dirigida al conocimiento y comprensión del entorno, la sensibilización ante conflictos, la optimización de la convivencia, la aceptación de la responsabilidad y el desarrollo de habilidades comunicativas. "Podríamos considerar el arte dramático como una pedagogía en sí misma", apunta Laferrière (1999, p. 56) intentando equiparar los principios, reglas y valores de ambas disciplinas.

La dramatización es una herramienta exploratoria que permite al individuo contemplarse, reflejarse y representar otros papeles diferentes al propio, lo que posibilita un conocimiento de la realidad desde diferentes ángulos y un análisis de las propias conductas por similitud, contraste o diferencia a las observadas. Así, la asunción de otros roles fomenta el desarrollo del juicio moral y los valores de sociabilidad, solidaridad, res- 
peto y diálogo entre compañeros, fruto del trabajo en equipo (Tejerina, 1997).

Además, las técnicas dramáticas incluyen un desarrollo emocional del alumnado, mejorando su capacidad de expresión, reconocimiento y control de emociones (Cruz, Caballero y Ruiz, 2013; Navarro, 2009; Ruiz de Velasco, 2000). Aprender a convivir implica, en un primer momento, el desarrollo de la identidad personal, para posteriormente, poder interactuar con los otros en un plano de igualdad y respeto. Tener conciencia de las emociones de uno mismo, con el fin de convivir de forma pacífica y solidaria, resolviendo todo conflicto de forma eficaz, es una necesidad básica en el ejercicio de una ciudadanía activa y participativa.

Por otra parte, la dramatización acoge características comunicativas y expresivas, puesto que reúne en sí distintas manifestaciones del lenguaje (verbal, corporal, audiovisual) y diversas artes y ciencias en conjunción (literatura, música, pintura, tecnología), fomentando con ello la educación integral del alumnado en cualquiera de sus etapas educativas. El desarrollo de la psicomotricidad, la expresión, la simbología, la imaginación y la creatividad son ingredientes fundamentales de la dramatización, que deben armonizarse en el individuo y dar como resultado el equilibro entre pensamiento y cuerpo (Laferrière, 2001). Por último, es precisamente este carácter transversal e interdisciplinar de la dramatización el que la convierte en un instrumento didáctico significativo para el desarrollo del conjunto de las competencias básicas y, más concretamente, según apunta Motos (2009, p. 9), el trabajo en la competencia social y ciudadana unida a las cuatro siguientes: competencia en comunicación lingüística, competencia cultural y artística, competencia para aprender a aprender y competencia en autonomía e iniciativa personal.

\section{Modelo de intervención didáctica}

Se pretende en este apartado ilustrar la revisión y justificación teóricometodológica expuesta anteriormente, mostrando un planteamiento didáctico consecuente que posibilite el desarrollo de la competencia social y ciudadana a través de dramatizaciones musicales del romancero tradicional.

Con tal fin, se formula, en primer lugar, el objetivo general que nos proponemos en dicha intervención didáctica: 
La dramatización musical del romancero en Educación Primaria para el desarrollo de la competencia social y ciudadana

María Isabel de Vicente-Yagüe Jara y María Marco Martínez

- Desarrollar la competencia social y ciudadana del alumnado de Educación Primaria, a través de un taller interdisciplinar de dramatización musical diseñado con estrategias de aprendizaje cooperativo y creativo.

Este objetivo general se articula, a su vez, en los objetivos específicos enunciados a continuación:

- Establecer vínculos interdisciplinares entre literatura y música para el fomento de una educación integral, contextualizada y holística, basada en competencias básicas.

- Promover la comprensión lectora y el disfrute lúdico de textos literarios clásicos procedentes del volumen Flor nueva de romances viejos, así como valorar su legado cultural y su proyección artística y social.

- Iniciar al alumnado en la escritura creativa de los clásicos en nuevos contextos significativos y con metodología intertextual.

- Fomentar en el alumnado prácticas de dramatización musical que persigan, a través del trabajo en equipo implicado, un diálogo respetuoso, solidario y democrático, necesario en el ejercicio de toda convivencia pacífica.

En segundo lugar, se expone el modelo de intervención didáctica en dos fases, sustentado en un aprendizaje basado en tareas para el desarrollo de las competencias básicas y, de modo especial, la competencia social y ciudadana.

Fase A: "Conociendo los romances"

- Coloquio inicial

El docente establece un coloquio con los alumnos, impulsando y activando el conocimiento de ciertos aspectos básicos del género poético: ritmo poético, rima, motivos poéticos, temática, estrategias descriptivas, estructura... Tras una lluvia de ideas estimulante y con ayuda del docente, esta tarea finaliza con la composición espontánea oral y conjunta de los alumnos de unos breves y sencillos poemas, con el fin de procurar desde su nivel educativo el ritmo, la rima y la entonación propia de este género literario.

- Lectura, comprensión y contextualización de los romances Se lleva a cabo la tarea de lectura y comprensión de ciertos romances escogidos de la antología Flor nueva de romances viejos 
de Menéndez Pidal (2010), romances que disfrutan de una versión musicalizada por el cantautor Joaquín Díaz González (2012), lo que permite una doble vertiente literario-musical para su aprendizaje:

- Romance del Enamorado y la Muerte

- Romance de la loba parda

- Romance del Prisionero

- Romance de la conquista de Alhama

Para generar sugestión imaginativa en el alumnado y estimular su empatía por la época en la que se gestaron tales poemas, el docente relata la contextualización histórica de los mismos como si de un cuento se tratase: la Edad Media es presentada en sus costumbres de ocio y trabajo, en sus clases sociales y, especialmente, en la figura del juglar.

- Escucha, aprendizaje e interpretación rítmica de los romances musicalizados

A través de la escucha de las versiones del cantautor Joaquín Díaz González (2012), el alumnado aprende las cadencias, ritmos y fraseo de los versos musicales. Posteriormente, a partir de las partituras rítmicas previamente diseñadas por el docente, los aprendices interpretan los romances con los diferentes instrumentos de percusión indeterminada (panderetas, claves, cascabeles...), además de con percusión corporal (pitos, pies y palmas).

Fase B: "De la poesía al teatro"

- Elaboración de composiciones literarias El alumnado realiza una transmodalización (Genette, 1982) del género poético al género teatral, a partir de la extracción lectora de los personajes y del argumento de cada uno de los romances. Se trata de una tarea grupal, con la asignación previa por parte del docente de un romance a cada grupo, el cual deberá elaborar los diálogos dramáticos. Se proporciona un organizador con las características comparadas de los géneros poético y teatral y con indicaciones puntuales para su correcto trasvase genérico.

- Elección de personajes para su posterior interpretación El docente abre un coloquio, en el que, de forma ordenada, cada alumno va escogiendo su personaje, argumentando su elección y opinando con perspectiva crítica sobre este. En aquellas situacio- 
nes en las que el mismo personaje quiera ser representado por dos discentes del mismo grupo, el maestro mediará y les ayudará a decidir.

- Confección del atrezzo y vestimenta de la Edad Media El alumnado investiga en el aula de informática a través del uso de las nuevas tecnologías el tipo de vestimenta y elementos decorativos de la época, así como las características contextuales medievales específicas, con el fin de elaborar un material de atrezzo adecuado por medio del material plástico facilitado por el docente.

- Dramatización en el aula

Una vez elaborado el atrezzo de los personajes y tras haber aprendido el guión teatral ideado por consenso cooperativo, cada grupo representa la dramatización oportuna frente a sus compañeros. La dramatización incluye la interpretación musical del romance correspondiente en la versión de Joaquín Díaz González, con la incorporación del instrumental de percusión indeterminada empleado en los ensayos de sesiones anteriores. Se pretende que el alumnado sea capaz de actuar con una fiel naturalidad al contexto histórico, literario y musical, respondiendo a las claves y pautas ofrecidas por el docente y participando de forma cooperativa e integrada con el conjunto de alumnos-actores.

\section{Conclusiones}

Conscientes de las dificultades a las que actualmente se enfrenta el profesorado, preocupado por cumplir con las exigencias curriculares vigentes y desprovisto de modelos didácticos que las satisfagan, hemos pretendido en este trabajo aportar soluciones de aprendizaje competencial a través de un innovadora metodología. Así pues, en consonancia con las nuevas demandas emanadas de las reformas legislativas educativas en el contexto de convergencia europea, se ha partido de una problemática inicial que en su vertiente general podemos resumir en el siguiente axioma: la pervivencia de una enseñanza conductista, que merma los proyectos interdisciplinares, impide el correcto desarrollo de las competencias básicas. Una vertiente más específica nos llevaba a indagar acerca de la metodología idónea para promover un aprendizaje significativo 
y globalizado por interacción entre literatura clásica y música que revirtiera en beneficio del desarrollo de la competencia social y ciudadana.

En este sentido, se ha presentado una metodología intertextual que conecta poesía y música a partir de la inspiración en textos clásicos del romancero tradicional, dotados de versiones musicales, para incluirla de modo conveniente en los planes curriculares de Educación Primaria, con el fin de fomentar la educación en la competencia social y ciudadana de los aprendices. Tal metodología dinamiza la puesta en práctica en el aula de dramatizaciones organizadas por los propios alumnos, que les permiten optimizar la lectura comprensiva en atención a la contextualización histórica, la lectura expresiva en atención al ritmo y la creatividad personal desde la motivación responsable de llevar a cabo una tarea cooperativa.

El factor motivador que conlleva toda tarea musical supone ya de entrada una gran ventaja educativa en prácticamente cualquier etapa en la que nos propusiéramos abordar un modelo didáctico de tales características con estos fines interdisciplinares, holísticos y, en definitiva, competenciales (Guerrero, 2008; Guerrero y Cano, 2009; Vicente-Yagüe, 2008, 2012, 2013). De igual forma, lo lúdico preside toda dramatización, por lo que, en conexión con el concepto antropológico de "homo ludens" de Huizinga (1998), que contempla el juego como una función esencial del individuo, la práctica teatral que defendemos contribuye a la creación de las reglas básicas de la cultura y la convivencia, así como al desarrollo de diversas funciones sociales y estrategias de aprendizaje en un contexto ficcional (Pérez Parejo, 2010). La estimulación del alumnado, pues, a través de un taller de dramatización musical en el aula presenta desde su mismo planteamiento soluciones propicias de aprendizaje.

Por otra parte, la realidad social plural que hoy en día cohabita en nuestras aulas, así como los posibles conflictos de convivencia ocasionados deben ser abordados principalmente desde perspectivas metodológicas que rechacen el individualismo del estudiante y afronten una dimensión ética y dialogante, precisamente a partir del desarrollo de una competencia como la que nos ocupa en este estudio (Conejo, 2012; Cuadrado y Fernández, 2011; Monzonís y Capllonch, 2014; Ortuño, Gómez y Ortiz, 2012). Por ello, el hecho de focalizar la atención en la dramatización y, más concretamente, la dramatización musical, responde a la voluntad didáctica de planificar con una perspectiva metodológica cooperativa, que permita la interacción, integración y convivencia social 
y pacífica del alumnado. La mejora de las relaciones sociales entre pares, así como el desarrollo de la autoestima y la confianza en sí mismos ya ha sido demostrado en investigaciones previas (De la Cruz, Lian y Morreau, 1998; George, 2000; Martín, 1992; Onieva, 2011; Waite, 1993).

Además, la naturaleza interdisciplinar de la dramatización ha sido advertida por ciertos investigadores, quienes potencian dicha condición conectando los recursos dramáticos literarios con materias como Música (Cabrera, Odena y Enric, 2006), Inglés (Breckenridge, 2006), Educación Física (Juez y de los Santos, 2011), Matemáticas e Historia (Onieva, 2011), entre otras. En este sentido, enseñar teatro en los niveles educativos iniciales difumina su condición de género literario para abordar, en realidad, una dimensión antropológica; el desarrollo cognitivo del individuo y el aprendizaje de estrategias sociales a través de técnicas dramáticas permite alcanzar facetas formativas que distan del simple aprendizaje literario disciplinar en aras de un aprendizaje integral del alumnado (Borda, 2004). El ser humano es un ser social y como tal debemos enfocar su educación en la sociedad actual, preocupándonos por la diversidad de acciones y expresiones sociales, culturales, lingüísticas que caracterizan a la humanidad.

Finalmente, el diseño de una intervención didáctica planificada en torno a Flor nueva de romances viejos, a través del recurso de las dramatizaciones musicales en la etapa de Educación Primaria, pretende ofrecer una oportunidad regulada para el desarrollo de la competencia social y ciudadana. Aunque parezca paradójico, la recuperación de lo antiguo en un programa totalmente innovador dirigido al aprendizaje de la cultura y tradición del romancero español, así como su conservación mediante la redifusión, ya sea bien de forma oral o escrita, es una necesidad acuciante y un proyecto olvidado en las aulas de hoy. El mismo Díaz González (1997) incidía en que este patrimonio cultural podría ser trabajado con gran provecho en la enseñanza básica, ya que reporta educación integral para la persona. Así pues, hemos de abogar por un tipo de metodología interdisciplinar e intertextual que conecte literatura, arte y vida, a través de estrategias expresivas, comunicativas, creativas, cooperativas, solidarias, participativas y democráticas, unidas todas ellas bajo el signo de la dramatización musical para el desarrollo de la competencia social y ciudadana. 
La dramatización musical del romancero en Educación Primaria para el desarrollo de la competencia social y ciudadana María Isabel de Vicente-Yagüe Jara y María Marco Martínez

\section{Referencias bibliográficas}

Asenjo Barbieri, F. (ed.) (1890). Cancionero musical de los siglos XV y XVI. Madrid: Tipografía de los huérfanos.

Bajtin, M. (1970). La poétique de Dostoievski. París: Seuil.

Barrios, Ma P. (2004). Música popular de tradición oral y su aplicación en contextos escolares. En E. Barcia (coord.). La tradición oral en Extremadura. Utilización didáctica de los materiales (pp. 339-381). Mérida: Consejería de Educación, Ciencia y Tecnología.

Borda, M ${ }^{a}$ I. (2004). Lo importante es el teatro. Primeras noticias. Revista de literatura, 206, 59-63.

Breckenridge, J. (2006). La dramatización de cuentos y leyendas en la clase de inglés como lengua extranjera. Acción Pedagógica, 15 (1), 128-135.

Cabrera, L., Odena, O., y Enric, J. (2006). Teatralizar la partitura para aprender mejor. Eufonía: Didáctica de la Música, 36, 113-123.

Caro, Ma T. (2006). Los clásicos redivivos en el aula (Modelo didáctico interdisciplinar en Educación Literaria). (Tesis Doctoral). Universidad de Murcia.

Conejo, P.A. (2012). El valor formativo de la Música para la educación en valores. Dedica. Revista de Educação e Humanidades, 2, 2012, 263-278.

Cruz, V., Caballero. P.A. y Ruiz, G. (2013). La dramatización como recurso didáctico para el desarrollo emocional. Un estudio en la etapa de educación primaria. Revista de investigación educativa, RIE, 31 (2), 392-410.

Cuadrado, I. y Fernández, I. (2011). La competencia social y el clima del aula como práctica inclusora en el contexto escolar. Organización y gestión educativa: Revista del Fórum Europeo de Administradores de la Educación, 19 (1), 22-25.

Decroly, O. y Boon, G. (1922). Hacia la Escuela renovada. Una primera etapa. Madrid: La Lectura.

De la Cruz, R., Lian, M., y Morreau, L. (1998). The Effects of Creative Drama on Social and Oral Language Skills of Children with Learning Disabilities. Youth Theatre Journal, 12, 89-94.

Delors, J. (1996). La Educación encierra un tesoro. Informe a la UNESCO de la Comisión Internacional sobre la educación para el Siglo XXI. Madrid: Santillana, ediciones UNESCO.

Devoto, D. (1943). Sobre la música tradicional española. Revista de Filología Hispánica, V, 344-366.

Díaz González, J. (1997). Panorama de la música tradicional. Eufonía: Didáctica de la música, 9, 7-12.

Díaz González, J. (2012). Cancionero de Romances [CD]. Madrid: Warner Music Spain.

Escamilla, A. (2009). Las competencias en la programación de aula. Infantil y primaria (3-12 años). Barcelona: Graó.

Fernández Bueno, M. (2009). La herencia literaria en la obra de Christoph Hein. Madrid: CSIC.

Fernández Herrero, B. (2010). La competencia comunicativa como base del desarrollo de la competencia social y ciudadana en el aula. Actualidades Investigativas en Educación, 10 (2),1-24. Recuperado de http://revista.inie.ucr.ac.cr/uploads/tx_magazine/ competencia.pdf 
La dramatización musical del romancero en Educación Primaria para el desarrollo de la competencia social y ciudadana

María Isabel de Vicente-Yagüe Jara y María Marco Martínez

Gabbay, C. (2010). Reflexiones teóricas en torno a la intertextualidad a partir del estudio de la lírica de Julio Cortázar. Comunicación presentada en el Congreso de Estudiantes Avanzados del Departamento de Estudios Románicos y Latinoamericanos, Universidad Hebrea de Jerusalén, Israel.

Genette, G. (1982). Palimpsestes. La littérature au second degré. París: Seuil.

George, N. (2000). Beneficial Use of Dramatics in the Classroom. New England Reading Association Journal, 36, 6-10.

Guerrero, P. (2008). Metodología de investigación en educación literaria (el modelo Ekfrástico). Murcia: Diego Marín.

Guerrero, P. y Cano, A.G. (2009). La intertextualidad poesía-música como estrategia didáctica. Un ejemplo del Cancionero. Lenguaje y textos, 29, 103-124.

Huizinga, J. (1998). Homo ludens. Madrid: Alianza.

Juez, A. y de los Santos, A. (2011). Aprendizaje cooperativo, metodología por proyectos y espacios de fantasía en educación física para primaria: (Re) construyendo la expresión corporal mediante la dramatización de cuentos e historietas infantiles. La Peonza: Revista de Educación Física para la paz, 6, 3-23.

Kilpatrick, W.H. (1918). The Proyect Method. Teachers College Record, 19 (4), 319-335.

Kristeva, J. (1978). Semiótica 1. Madrid: Fundamentos.

Laferrière, G. (1999). La pedagogía teatral, una herramienta para educar. Educación social: Revista de intervención socioeducativa, 13, 54-65.

Laferrière, G. (2001). Prácticas creativas para una enseñanza dinámica: la dramatización como herramienta didáctica y pedagógica. Ciudad Real: Ñaque.

Ley Orgánica 2/2006, de 3 de mayo, de Educación (BOE, 4/05/2006).

Llach, S. y Alsina, A. (2009). La adquisición de competencias básicas en Educación Primaria: una aproximación desde la Didáctica de la Lengua y de las Matemáticas. REIFOP, 12 (3), 71-85. Recuperado de http//www.aufop.com

Lozano, M. (2004). Hacia una nueva Flor de Romances Nuevos: Experiencia didáctica con el Romancero Tradicional. En E. Barcia (coord.). La tradición oral en Extremadura. Utilización didáctica de los materiales (pp. 249-278). Mérida: Consejería de Educación, Ciencia y Tecnología.

Marina, J.A. y Bernabeu, R. (2007). Competencia social y ciudadana. Madrid: Alianza.

Martín, X. (1992). El role-playing, una técnica para facilitar la empatía y la perspectiva social. Comunicación, Lenguaje y Educación, 15, 63-67.

Martínez Torner, E. (1923). Indicaciones prácticas sobre la notación musical de los romances. Revista de Filología Española, X (4), 389-394.

MEC (2006). Real Decreto 1513/2006, de 7 de diciembre, por el que se establecen las enseñanzas mínimas de la Educación primaria (BOE, 8/12/2006).

Mendoza, A. (coord.) (2012). Leer hipertextos. Del marco hipertextual a la formación del lector literario. Barcelona: Octaedro.

Menéndez Pidal, R. (1953). Romancero hispánico (hispano-portugués, americano y sefardí). Teoría e investigación. Madrid: Espasa-Calpe.

Menéndez Pidal, R. (1973). Sobre la geografía folklórica, ensayo de un método. En Estudios sobre el Romancero (pp. 229-338). Madrid: Espasa-Calpe. 
La dramatización musical del romancero en Educación Primaria para el desarrollo de la competencia social y ciudadana María Isabel de Vicente-Yagüe Jara y María Marco Martínez

Menéndez Pidal, R. (ed.) (2010). Flor nueva de romances viejos (58 ed.). Madrid: Espasa Libros.

Monzonís, N. y Capllonch, M. (2014). La educación física en la consecución de la competencia social y ciudadana. Retos: nuevas tendencias en educación física, deporte y recreación, 25, 180-185.

Moreno, C. (2009). Los márgenes del romancero: Versiones minoritarias, fragmentarias y anómalas. Pandora, 9, 253-271.

Motos, T. (2009). El teatro en la educación secundaria: fundamentos y retos. Creatividad y Sociedad, 14, 1-35. Recuperado de http://www.creatividadysociedad.com

Mudarra, A. de (1546). Tres libros de música en cifras para vihuela. Recuperado de http:// bibliotecadigitalhispanica.bne.es

Navarro, Ma R. (2009). Dramatización y educación emocional. En P. Fernández (coord.), Avances en el estudio de la inteligencia emocional (pp. 545-548). Santander: Fundación Marcelino Botín.

Onieva, J.L. (2011). La dramatización como recurso educativo: estudio de una experiencia entre estudiantes malagueños de un centro escolar concertado y adolescentes puertorriqueños en situación de marginalidad. (Tesis Doctoral). Universidad de Málaga.

Ortuño, J. y Gómez, C. J. y Ortiz, E. (2012). La evaluación de la competencia educativa social y ciudadana desde la didáctica de las ciencias sociales. Un estado de la cuestión. Didáctica de las Ciencias Experimentales y Sociales, 26, 53-72.

Pérez Parejo, R. (2010). "Homo ludens" en la dramatización: la dimensión antropológica de la actividad dramática. Escuela abierta: revista de Investigación Educativa, 13, 55-68.

Pisador, D. (1552). Libro de música de vihuela. Recuperado de http://imslp.org

Ruiz de Velasco, A. (2000). La dramatización como forma de desarrollar la inteligencia emocional. Indivisa: Boletín de estudios e investigación, 1, 191-196.

Salinas, F. de (1577). De musica libri septem. Recuperado de http://imslp.org

Tejerina, I. (1997). La educación en valores y el teatro. Apuntes para una reflexión y propuesta de actividades. En J. García Padrino y P. Cerrillo (coords.), Teatro infantil y dramatización escolar (pp. 97-118). Castilla-La Mancha: Servicio de Publicaciones de la Universidad de Castilla-La Mancha

Torres, J. (2006). Globalización e interdisciplinariedad: el currículo integrado. Madrid: Morata.

Unión Europea (2006). Recomendación del Parlamento Europeo y del Consejo, de 18 de diciembre de 2006, sobre las competencias clave para el aprendizaje permanente (2006/962/CE). (Diario Oficial de la Unión Europea, 30/12/2006).

Vicente-Yagüe, $M^{a}$ I. de (2008). El comparativismo en la educación literaria y musical: propuesta de innovación metodológica. Educatio Siglo XXI, 26, 241-266.

Vicente-Yagüe, $M^{a}$ I. de (2012). Miguel Hernández y sus trovadores ideológicamente comprometidos. Una experiencia musical en la educación literaria. Lenguaje y textos. Revista de la Sociedad Española de Didáctica de la Lengua y la Literatura, 35, 77-83.

Vicente-Yagüe, M ${ }^{\mathrm{a}}$ I. de (2013). La intertextualidad literario-musical. Una estrategia didáctica para la animación a la lectura y la audición musical. Barcelona: Octaedro.

Waite, L. (1993). Drama Therapy in Small Groups with the Developmentally Disabled. Social Work with Groups: A Journal of Community and Clinical Practice, 16, 95-108. 
